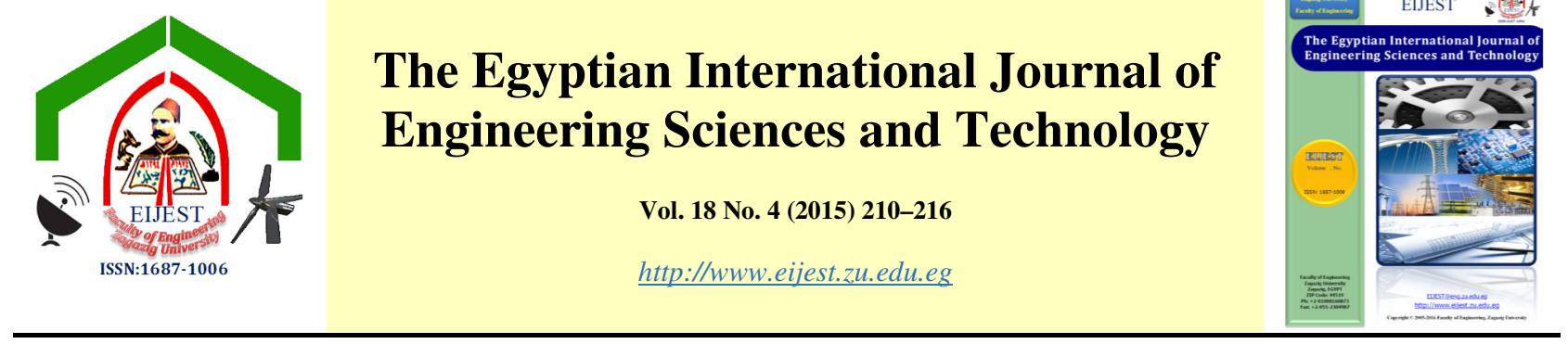

\title{
Electric potential calculation and electric field simulation around an earthing system of wind turbines
}

\author{
M. Talaat ${ }^{\mathrm{a}^{*}}$, M. A. Farahat ${ }^{\mathrm{a}}$ and M. Osman ${ }^{\mathrm{b}}$ \\ ${ }^{a}$ Electrical Power \& Machines Department, Faculty of Engineering, Zagazig University, Egypt \\ ${ }^{b}$ M. Sc. Engineering, Faculty of Engineering, Zagazig University, Egypt
}

\begin{tabular}{|c|c|}
\hline ART I CLE INFO & A B S T RA C T \\
\hline $\begin{array}{l}\text { Article history: } \\
\text { Received } 30 \text { August } 2015 \\
\text { Received in revised form } \\
26 \text { Sept. } 2015 \\
\text { Accepted } 29 \text { Sept. } 2015 \\
\text { Available online Oct. } 2015 \\
\end{array}$ & $\begin{array}{l}\text { A mathematical model for estimating the electric potential at the ground surface of } \\
\text { an earthing system of wind turbines using ring electrode is presented. This model } \\
\text { depends on the induced charge resulting from the injected current in the ring } \\
\text { electrode that is buried in the earthing layers and connecting with turbine body. A } \\
\text { three dimension numerical model to analyse wind turbine earthing systems is }\end{array}$ \\
\hline $\begin{array}{l}\text { Keywords: } \\
\text { Wind turbine } \\
\text { Lightning protection } \\
\text { Earthing system } \\
\text { Electric field } \\
\text { Finite element method }\end{array}$ & $\begin{array}{l}\text { proposed. The proposed technique depends on the determination of the electric } \\
\text { field intensity and the distribution of the injected current into the surrounding soil } \\
\text { around an earthing system of wind turbine. The finite element method is used for } \\
\text { this purpose. The proposed technique is applicable to simple and complex earthing } \\
\text { systems with uniform soil. }\end{array}$ \\
\hline
\end{tabular}

\section{Introduction}

Earthing system provides a low impedance path to high currents to prevent over-voltages and potential gradient. Grounding grids can be used as a common reference to all electrical and electronic equipment in the system during steady state and transient conditions [1, 2]. Earthing electrodes may be formed as driven vertical or horizontal rods or a buried plate or a grid. A ring earth electrode resistance, number of auxiliary rods and the combination of them should be taken into consideration to reduce the earthing system resistance [3].

Lightning strikes and power system faults provide high currents which may cause damage to human life or electrical equipment. Wind turbines are often struck by lightning due to their special shape, complex construction and the fact that they are usually placed in isolated locations, mainly at higher altitudes with high resistivity soil. Under Lightning strikes and ground fault conditions, the maximum potential gradients at the earth's surface may be of sufficient magnitude to damage personal life or equipment. So, the buried ground rod is often used to ground system. As the depth of the buried ground rod is increased, the earth surface voltage decreases [4]. Also, the position of maximum surface voltage varies with the depth of the buried ground rod. On the other hand, the surface potential distribution during ground faults or lightning strikes can be determined using scale models in an electrolytic tank [5].

The ability of a horizontal earth electrode to reduce the earth potential rise is limited because, beyond a certain length known as the effective length, no further reduction is obtained. The effective length was determined experimentally by incrementally increasing the length of the test electrode [6].

Finite element method (FEM) is used as a numerical technique for finding approximate solutions to boundary value problems for partial differential equations. [7].

* Corresponding author: Tel: +2010050305 49 ; E-mail Address: m_mtalaat@eng.zu.edu.eg 
A simplified ideal wind turbine foundation will be used [8]. The wind turbine foundation is consisted of reinforced bar is structured by copper frame. The foundation connected with earthing system. This grounding system is consisted of a combination of a ring earth electrode with vertical rods.

In this paper the electrical potential distribution, electrical field distribution in three dimension and current density distribution due to the combination of ring earth electrode with vertical rods for wind turbine as recommended in IEC TR 61400-24:2002 [9] is presented. FEM electrostatic calculations with a wind turbine foundation and various electrode configurations are performed using the partial differential equation toolbox under MATLAB library

\section{Mathematical model}

The electric potential distribution $V$ due to ring electrode subjected to electric charge can be obtain as,

$$
V=\int_{\rho}^{\infty} \mathrm{E}(\rho) d \rho
$$

where, $\mathrm{E}$ is the electric field intensity and $\rho$ represents the radius of the ring electrode in $\mathrm{m}$, and can be analyzed in two components of $x-y$ plane, see Fig. 1.



Fig. 1: Schematic diagram of two-dimensions of ring electrode energized with electric current.

The electric field intensity can be obtained from,

$$
\mathrm{E}=\frac{\mathrm{J}_{e}}{\sigma} \quad V / m
$$

where, $J_{e}$ is the electrostatic current density in $A / \mathrm{m}^{2}$ and $\sigma$ is the soil conductivity of the medium.

A current density due to the leakage current, $I_{\text {leakage }}$ which will cover the area of the earth electrode [10].

$$
\begin{aligned}
\mathrm{J}_{e} & =\left(\frac{I_{\text {leakage }}}{4 \pi \rho^{2}}\right) \quad A / \mathrm{m}^{2} \\
\therefore \quad \mathrm{E} & =\frac{I_{\text {leakage }}}{4 \pi \sigma \rho^{2}} \quad \mathrm{~V} / \mathrm{m}
\end{aligned}
$$

Then the electric potential can be calculated using equation (1) as,

$$
\begin{gathered}
\mathrm{V}=\int_{\rho}^{\infty} \frac{I_{\text {leakage }}}{4 \pi \sigma \rho^{2}} d \rho \\
V=\frac{I_{\text {leakage }}}{4 \pi \sigma \rho} \quad \text { Volt } \\
\therefore d V=\frac{d I_{\text {leakage }}}{4 \pi \sigma \rho}
\end{gathered}
$$

where, $I_{\text {leakage }}$ is the leakage current due to a current $I$ flowing through the ring electrode with perimeter of the ring electrode with length change $\rho d \emptyset[10]$, see Fig. 1.

$$
\begin{aligned}
d I_{\text {leakage }} & =\left(\frac{I}{2 \pi \rho}\right) \times \rho d \phi \\
d I_{\text {leakage }} & =\left(\frac{I}{2 \pi}\right) d \phi \quad A
\end{aligned}
$$

Substituting in equation (6)

$$
\begin{aligned}
& \therefore d V=\left(\frac{1}{4 \pi \sigma}\right) \times\left(\frac{I}{2 \pi}\right) \times\left(\frac{1}{\rho}\right) d \emptyset \\
& V=\left(\frac{1}{4 \pi \sigma}\right) \times\left(\frac{I}{2 \pi}\right) \times \int_{0}^{2 \pi}\left(\frac{1}{\rho}\right) d \emptyset
\end{aligned}
$$

In three dimensions the value of $\rho$ in this equation changes to $v$ as shown in Fig. 2.

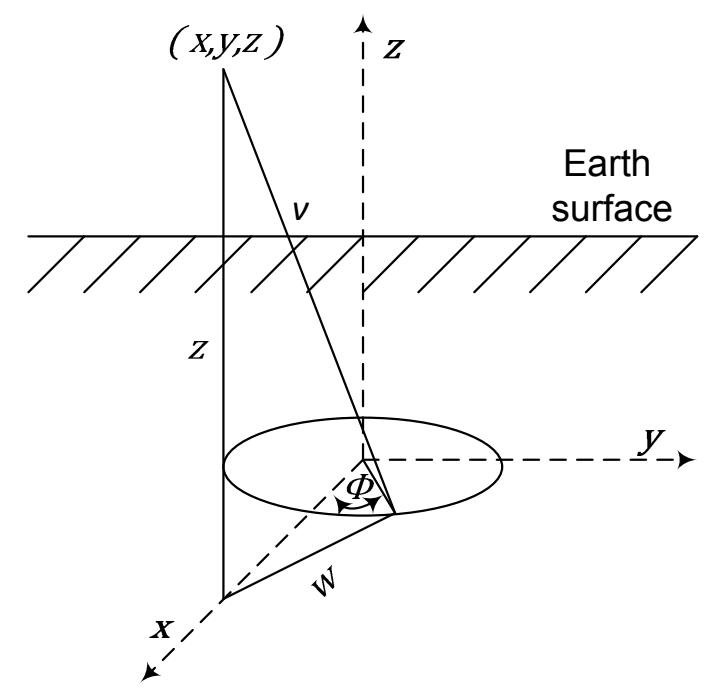

Fig. 2: The three-dimensions of ring electrode [10].

$$
V=\left(\frac{1}{4 \pi \sigma}\right) \times\left(\frac{I}{2 \pi}\right) \times \int_{0}^{2 \pi}\left(\frac{1}{v}\right) d \emptyset
$$

To obtain the value of $v$, first the value of $w$ should be obtained [10], see Fig. 3. 


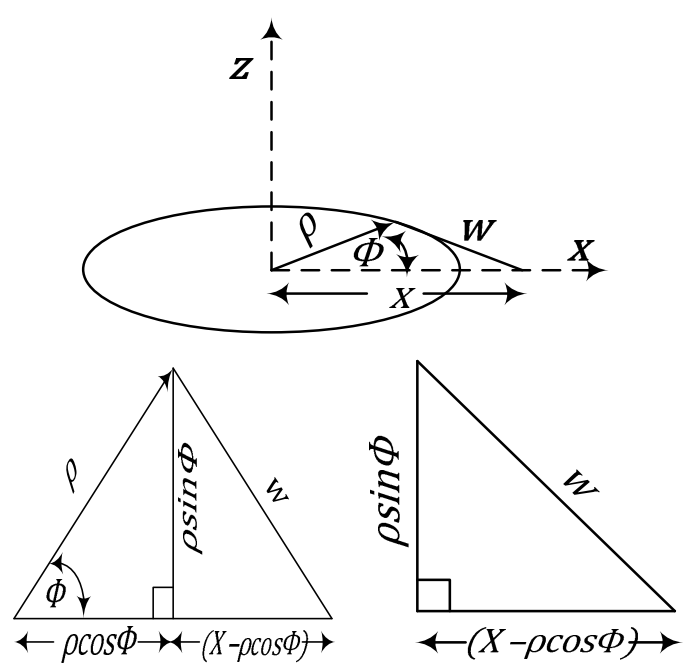

Fig. 3: The two-dimensions of ring electrode and analysis of its components.

$$
\begin{gathered}
w=\sqrt{\left((x-\rho \cos \phi)^{2}+\left(\rho^{2} \sin ^{2} \phi\right)\right)} \\
w=\sqrt{\left(x^{2}-2 x \rho \cos \phi+\rho^{2} \cos ^{2} \phi+\rho^{2} \sin ^{2} \phi\right)} \\
w=\sqrt{\left(x^{2}+\rho^{2}-2 x \rho \cos \phi\right)}
\end{gathered}
$$

Which agrees with Sunde's ring earth electrode equation [11].

In the three dimension value of $v$ can be obtained by adding the dimension of z-axis.

$$
v=\sqrt{\left(x^{2}+\rho^{2}+z^{2}-2 x \rho \cos \phi\right)}
$$

Substituting in equation (8) with the new value of $v$

$$
\begin{gathered}
V=\frac{1}{4 \pi \sigma} \times \frac{I}{2 \pi} \int_{0}^{2 \pi} \frac{d \phi}{\sqrt{\left(x^{2}+\rho^{2}+z^{2}-2 x \rho \cos \phi\right)}} \\
V=\left(\frac{1}{4 \pi \sigma}\right) \times\left(\frac{I}{2 \pi}\right) \times\left(\frac{4}{\sqrt{\{x+\rho\}^{2}+z^{2}}}\right) * F(\alpha)
\end{gathered}
$$

where, $F(\alpha)$ is the complete elliptic integral of the $1^{\text {st }}$ kind of ring electrode, see Appendix A.

\section{Simulation model}

For the present model, a simplified ideal foundation for wind turbine earthing system [8] recommended in IEC TR 61400-24:2002 [9] with the following assumptions is assumed :

- a tower is not considered and the lightning current is assumed to be strike on the top surface of the foundation
- the foundation is made of copper ring electrode with thickness $250 \mathrm{~mm}$ and the area of the base $13 m \times 13 m$

- a reinforced bar in the foundation is simulated by a copper electrode.

Figure 4, shows a combination of ring earth electrode with vertical rods. All dimensions in $\mathrm{mm}$.The electrical potential $(V)$ is assumed to be one per unit ( $V=1$ p.u.), so the simulation program will be available for any different value of the applied potential.

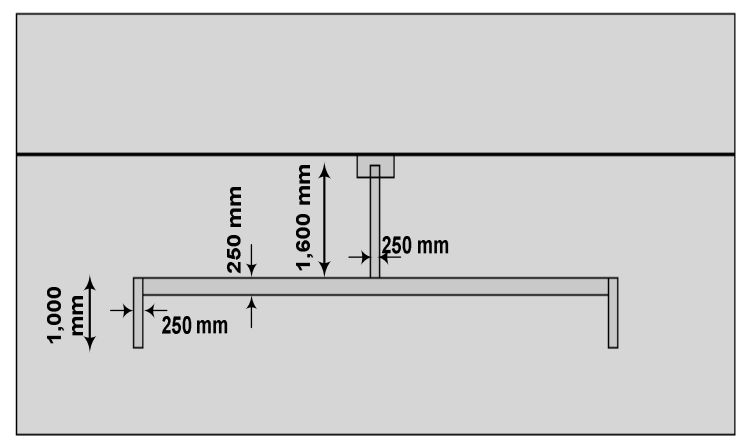

Fig. 4: Dimension of wind turbine earthing system according to IEC TR 61400-24:2002 [9].

The electric potential on the surface of the electrodes is given as $V=1 p . u$. and at the ground surface $\mathrm{V}=$ 0 this is achieved by applying Drichlet equation. While Neumann equation satisfy the boundary condition $\partial V / \partial n=0$ everywhere else; all boundary conditions are explained in Fig.5.



Fig. 5: Boundary conditions of wind turbine earthing system.

Numerical calculations were performed using partial differential equations (PDE) solutions [7, 12-13]. In general, a two-dimensional (2D) problem space is divided into triangular elements and the variables are approximated by second or third order polynomials in each element, see Fig. 6. 


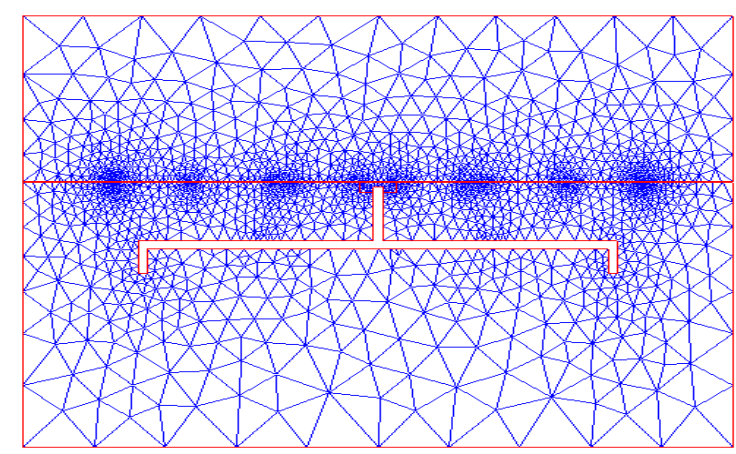

Fig. 6: Mesh mode of wind turbine earthing system.

Different types of soils have been used in this work to get different simulation for building the grounding system. Soils have been illustrated in Table 1.

Table 1. Typical resistivity and relative permittivity for different types of earth soil.

\begin{tabular}{|l|l|c|c|}
\hline & Soil & $\begin{array}{c}\text { Resistivity } \\
(\Omega \cdot \boldsymbol{m})\end{array}$ & $\begin{array}{c}\text { Relative } \\
\text { permittivity }(\boldsymbol{\varepsilon})\end{array}$ \\
\hline 1 & Loamy dry & $30-50$ & $4-6$ \\
\hline 2 & Clayey wet & $14-30$ & $10-15$ \\
\hline 3 & Sandy wet & $60-130$ & $15-30$ \\
\hline
\end{tabular}

\section{Results}

After applying lightning strike with electrical voltage equal 1 per unit to the wind turbine earthing system, the potential distribution, the electric field simulation and the surface current density were obtained for different soils as shown in Table 2.

Table 2. Conductivity, Maximum current density and Maximum electric field for different types of earth soil.

\begin{tabular}{|c|c|c|c|c|}
\hline & Soil & $\begin{array}{c}\text { Conductivity } \\
(\Omega . \boldsymbol{m})^{-\mathbf{1}}\end{array}$ & $\begin{array}{c}J_{\max .} \\
(\boldsymbol{p} . \boldsymbol{u} .)\end{array}$ & $\begin{array}{c}\boldsymbol{E}_{\max .} \\
(\boldsymbol{p} . \boldsymbol{u} .)\end{array}$ \\
\hline 1 & Loamy dry & 0.025 & 0.203 & 8.1064 \\
\hline 2 & Clayey wet & 0.04545 & 0.368 & 8.0966 \\
\hline 3 & Sandy wet & 0.01053 & 0.085 & 8.0931 \\
\hline
\end{tabular}

Also the electric field components in $\rho$ and $z$ directions are obtained and are given in Table 3 .

Table 3. Maximum components of electric field at $\rho$-axis and z-axis for different types of earth soil.

\begin{tabular}{|c|c|c|c|}
\hline & $\begin{array}{c}\text { Types of } \\
\text { soils }\end{array}$ & $\begin{array}{c}\text { Max. } \\
E_{\rho}(p . u .)\end{array}$ & $\begin{array}{c}\text { Max. } E_{z}(p . u .) \\
\text { at ground surface }\end{array}$ \\
\hline 1 & Loamy dry & 4.9157 & 0.6393 \\
\hline 2 & Clayey wet & 4.8541 & 0.8199 \\
\hline 3 & Sandy wet & 4.8333 & 0.8825 \\
\hline
\end{tabular}

\subsection{Electrical potential distribution}

Figures 7, 8, and 9 show that the potential distribution in Loamy dry soil has a big effect more than in Clayey wet and Sandy wet. This can be explained with the fact of soil with low dielectric constant has high electric potential distribution.

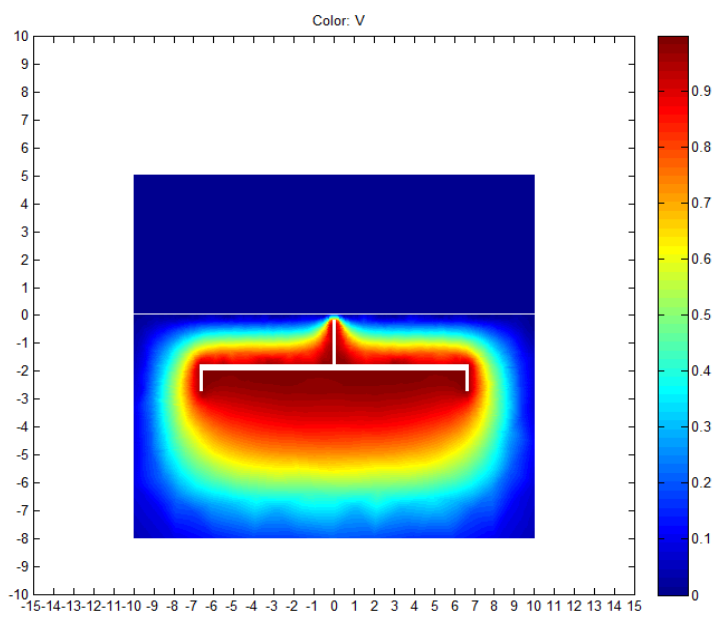

Fig. 7: Electrical potential distribution in p.u. for Loamy dry soil.

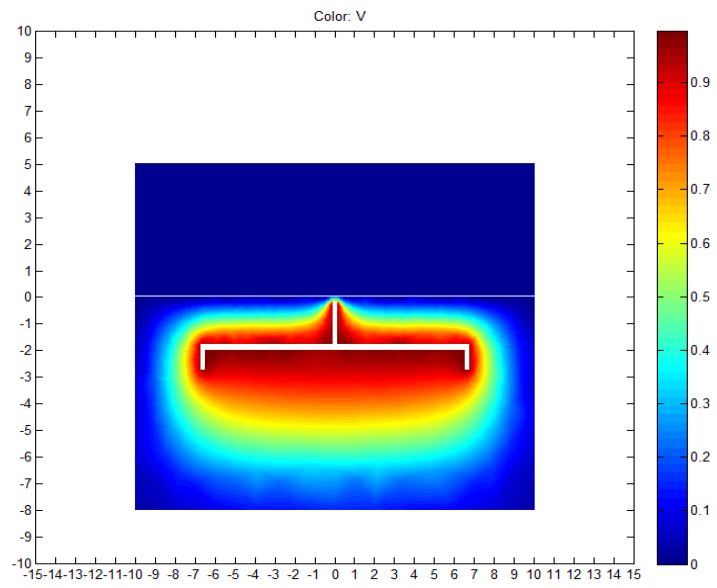

Fig. 8: Electrical potential distribution in p.u. for Clayey wet soil.

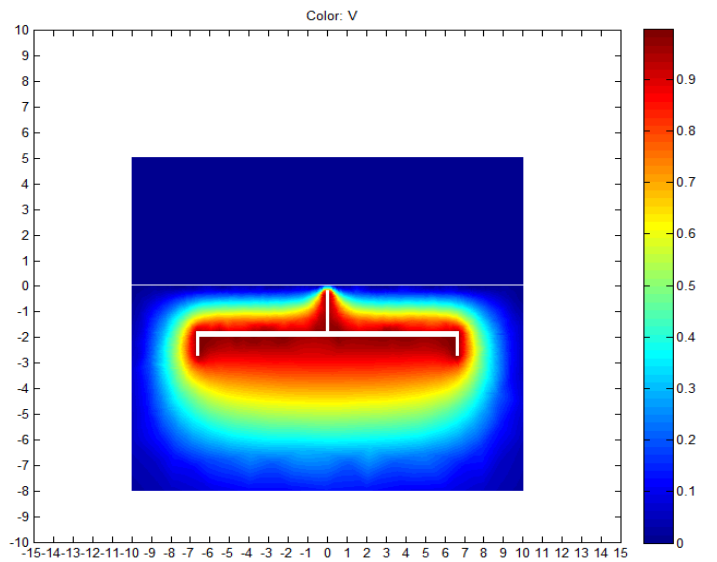

Fig. 9: Electrical potential distribution in p.u. for Sandy wet soil. 


\subsection{Electrical field distribution}

Figures 10, 11, and 12 show that the electrical field distribution due to different types of soils is slightly different but the maximum value of electric field exists at the top of vertical rod appear in man hall, see Fig. 5, at the ground surface.



Fig. 10: Electrical field distribution in 3-D in p.u. for Loamy dry soil.

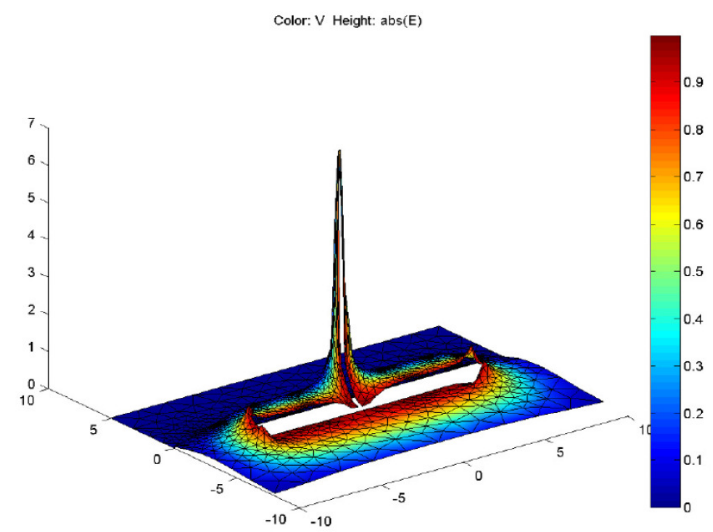

Fig. 11: Electrical field distribution in 3-D in p.u. for Clayey wet soil.

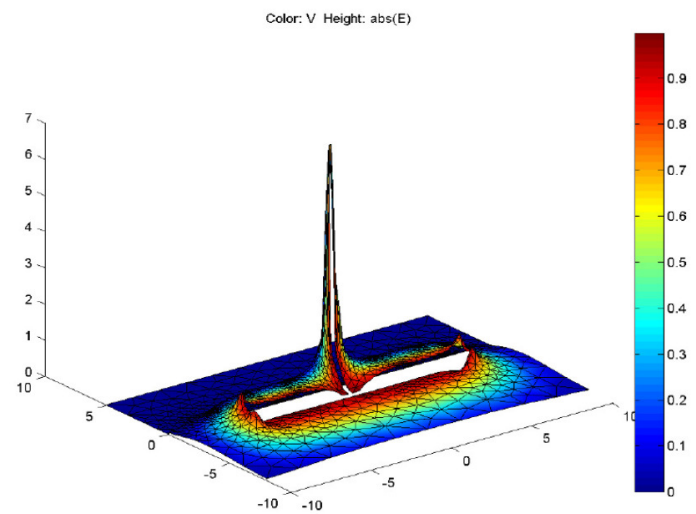

Fig. 12: Electrical field distribution in 3-D in $p . u$. for Sandy wet soil.

\subsection{Current density distribution}

Figures 13, 14, and 15 show that the maximum value of the current density be at vertical rod. The current density distribution decreases with the increasing of soil relative permittivity.

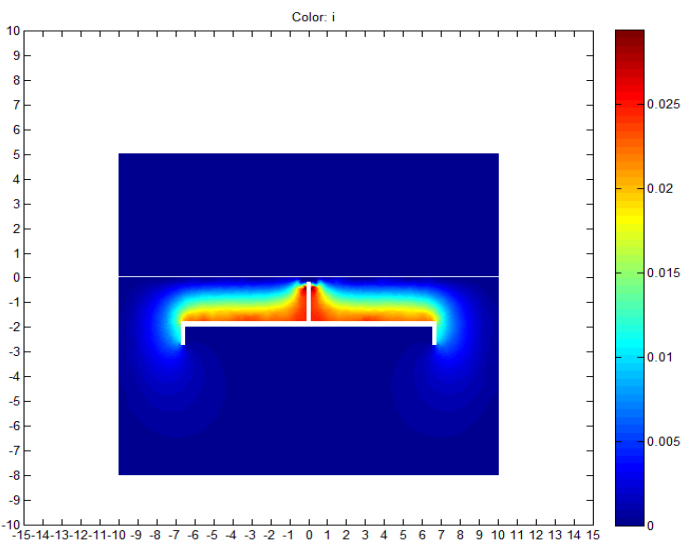

Fig. 13: Current density distribution in $p . u$. for Loamy dry soil.



Fig. 14: Current density distribution in $p . u$. for Clayey wet soil.

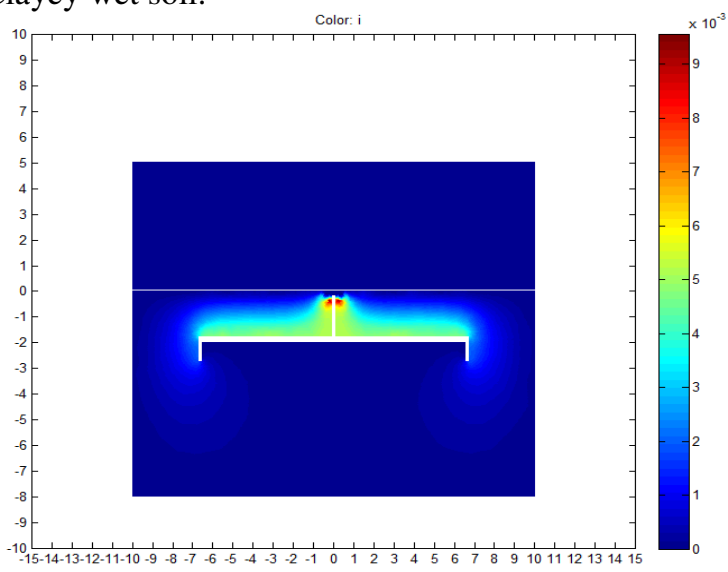

Fig. 15: Current density distribution in p.u. for Sandy wet soil. 
Also, from these Figures it is clear that the loamy dry soil is in medium values with respect to other types of soils for the current density value but its distribution is very high near the ground surface.

Current density is concentrated only at the top of the main vertical rod for both of clayey and sandy wet soils. The value of current density in clayey wet is the highest due to the high concentration and type of saturating ions existing in it that support the current values.

\section{Conclusion}

A mathematical model for estimating the electrical potential, the induced electrical field and current density distribution is presented. This model is in three dimensions of the simulation. The finite element method is used as a numerical method for simulating the electric potential, electric field and current densities. The partial differential equation toolbox of the MATLAB software is used. The potential is represented by per-unit system to be available for any value of applied potential. After simulation the type of Loamy dry soil gives good values for each of potential, electrical field and current density distribution. The simulation shows that the current density distribution decreases with the increasing of soil relative permittivity.

\section{Appendix A}

$$
V=\frac{1}{4 \pi \sigma} \times \frac{I}{2 \pi} \int_{0}^{2 \pi} \frac{d \phi}{\sqrt{\left(x^{2}+\rho^{2}+z^{2}-2 x \rho \cos \phi\right)}}
$$

Now, from [10], let $\emptyset=180-2 \alpha$

$$
\begin{gathered}
\cos \phi=\cos (\pi-2 \alpha)=-\left(1-2 \sin ^{2} \alpha\right) \\
\therefore v^{2}=x^{2}+\rho^{2}+z^{2}-2 x \rho \cos \phi \\
=x^{2}+\rho^{2}+z^{2}+2 x \rho\left(1-2 \sin ^{2} \alpha\right) \\
=x^{2}+\rho^{2}+z^{2}+2 x \rho-4 x \rho \sin ^{2} \alpha \\
=(x+\rho)^{2}+z^{2}-4 x \rho \sin ^{2} \alpha
\end{gathered}
$$

Taking $\left\{(x+\rho)^{2}+z^{2}\right\}$

$$
v^{2}=\left\{(x+\rho)^{2}+z^{2}\right\} *\left(1-\frac{4 x \rho \sin ^{2} \alpha}{(x+\rho)^{2}+z^{2}}\right)
$$

Let $K^{2}=\frac{4 x p}{\left((x+\rho)^{2}+z^{2}\right)}$

$$
\begin{gathered}
\therefore v^{2}=\left\{(x+\rho)^{2}+z^{2}\right\} *\left(1-K^{2} \sin ^{2} \alpha\right) \\
V=\frac{1}{4 \pi \sigma} \times \frac{I}{2 \pi} \times \int_{0}^{2 \pi} \frac{d \phi}{\sqrt{\left(\{x+\rho\}^{2}+z^{2}\right)\left(1-K^{2} \sin ^{2} \alpha\right)}}
\end{gathered}
$$

where,

$$
\begin{gathered}
\phi=180-2 \alpha \quad \text { If } \phi=0 \quad \alpha=0.5(180-0)=\frac{\pi}{2} \\
d \phi=-2 d \alpha \quad \text { If } \phi=2 \pi \alpha=0.5(\pi-2 \pi)=-\frac{\pi}{2} \\
V=\frac{1}{4 \pi \sigma} \times \frac{I}{2 \pi} \times \int_{\frac{\pi}{2}}^{\frac{-\pi}{2}} \frac{-2 d \alpha}{\sqrt{\left(\{x+\rho\}^{2}+z^{2}\right)\left(1-K^{2} \sin ^{2} \alpha\right)}} \\
V=\frac{2}{4 \pi \sigma} \times \frac{I}{2 \pi} \times \int_{0}^{\frac{\pi}{2}} \frac{-2 d \alpha}{\sqrt{\left(\{x+\rho\}^{2}+z^{2}\right)\left(1-K^{2} \sin ^{2} \alpha\right)}} \\
V=\frac{1}{4 \pi \sigma} \times \frac{I}{2 \pi} \times \frac{4}{\sqrt{\{x+\rho\}^{2}+z^{2}}} \int_{0}^{\frac{\pi}{2}} \frac{d \alpha}{\sqrt{\left(1-K^{2} \sin ^{2} \alpha\right)}} \\
\text { Let } F(\alpha)=\int_{0}^{\frac{\pi}{2}} \frac{1}{\sqrt{\left(1-K^{2} \sin ^{2} \alpha\right)}} d \alpha \\
V=\left(\frac{1}{4 \pi \sigma}\right) \times\left(\frac{I}{2 \pi}\right) \times\left(\frac{4}{\sqrt{\{x+\rho\}^{2}+z^{2}}}\right) \times F(\alpha)
\end{gathered}
$$

where, $F(\alpha)=\int_{0}^{\frac{\pi}{2}} \frac{1}{\sqrt{\left(1-K^{2} \sin ^{2} \alpha\right)}} d \alpha$ is called the complete elliptic integral of the $1^{\text {st }}$ kind [14].

\section{References}

[1] L. D. Grcev, "Computer analysis of transient voltage in large grounding systems", IEEE Trans. Power Delivery, Vol. 11, No. 2, pp. 815-823, 1996.

[2] L. D. Grcev and M. Heimbach, "Frequency dependent and transient characteristics of substation grounding systems", IEEE Trans. Power Delivery, Vol. 12, No. 1, pp.172-178, 1997.

[3] Damir Cavka, Dragan Poljak, Vicko Doric, and RankoGoic, "Transient analysis of grounding systems for wind turbines", Renewable Energy, Vol. 43, pp. 284-291, 2012.

[4] Li-Hsiungchen, Jiann-Fuhchen, Tsorng-Juu Liang and Wen-I Wary, "Calculation of ground resistance and step voltage for buried ground rod with insulation lead", Electrical Power Systems Research, Vol. 78, pp. 995-1007, 2008.

[5] S. Ghoneim and H. Hirsch, "Earth surface potential calculation using scale model with scaling time of applied impulse current", Proceedings of the 16th International Symposium on High Voltage Eng. (ISH 2009), pp. 1-6, Paper G-12, 2009.

[6] Ahmed El Mghairbi, "Assessment of earthing systems and enhancement of their performance", $\mathrm{Ph}$. D. Thesis, Cardiff University, 2012. 
[7] M. Talaat, "Electric field simulation along silicone rubber insulators surface", in: Proceedings of the 17th International Symposium on High Voltage Engineering, (ISH 2011) Germany. Paper A-22, 2011, pp. 1-6.

[8] Y. Yoh, F. Toshiaki and U. Toshiaki, "How does ring earth electrode effect to wind turbine?", 42nd International Universities Power Engineering Conference, UPEC 2007. pp. 796 - 799, 2007

[9] IEC Technical Report, "Wind Turbine Generation System 24: Lightning Protection", TR61400-24, 2002.

[10] Y. Yoh and F. Toshiaki, "Equivalent equation of earth resistance for ring electrode of wind turbine", European Wind Energy Conference and Exhibition (EWEC2010), PO.349, Warsaw, Poland, 2010
[11] Alex Martinez and Alan P. Byrnes, "Modelling dielectricalconstant values of geologic materials: an aid to groundpenetrating radar data collection and interpretation", Earth Sciences, Bulletin 247, part I, pp. 1-16, 2002.

[12] M. Talaat "A simulation model of fluid flow and streamlines induced by non-uniform electric field" IEEE, 14th International Middle East Power Systems Conference MEPCON'10, pp. 371-375, Cairo University, Egypt, December 19-21, 2010.

[13] M. Talaat and A. El-Zein, "A numerical model of streamlines in coplanar electrodes induced by non-uniform electric field", Journal of Electrostatics Vol. 71, No. 3, pp. 312-318, 2013.

[14] B. C. Carlson, "Numerical computation of real or complex elliptic integrals", Numerical Algorithms, Vol. 10, No. 1, pp. 13-26, 1995. 